\title{
Why Are Carbon Molecular Sieves Interesting?
}

\author{
Erica C. de Oliveira, Cléo T. G. V. M. T. Pires and Heloise O. Pastore* \\ Instituto de Química, Universidade Estadual de Campinas, CP 6154, 13083-970 Campinas-SP, Brazil
}

\begin{abstract}
Este trabalho descreve os métodos de produção e os usos potenciais das peneiras moleculares de carbono. A principal rota sintética para estes materiais é a replicação, onde uma peneira molecular de sílica ou aluminossilicato é usada como gabarito (template) para o crescimento de uma fase carbonácea nos seus canais e cavidades. Estes materiais podem ter aplicações tão variadas como separação, adsorção e armazenamento de gases, como eletrodos em baterias e como suportes de catalisadores, todas elas extremamente dependentes da porosidade da peneira molecular de carbono.
\end{abstract}

This paper describes the production methods and the prospective uses of carbon molecular sieves. The main route to these materials is replication synthesis, where a silica or aluminosilicate molecular sieve is used as template to grow the carbonaceous phase in the voids. These materials may have applications as varied as in separation, adsorption and storage of gases, as electrodes in batteries, and as catalyst supports, all of them highly dependent on the molecular sieve porosity.

Keywords: carbon molecular sieves, electrodes, batteries, replication, template

\section{Introduction}

As the $21^{\text {st }}$ century begins, the scientific community turns its eyes again to carbon. The production of buckyballs first and of carbon nanotubes later, and all the perspectives they brought in terms of novelty and of improvement of life quality, made the element again attractive for research and development. This work deals with organized carbon, not as crystalline as $\mathrm{C}_{60}$ or nanotubes, but as useful as or even more useful than these two.

Two classes of materials are broadly called carbon molecular sieves. One of them, first synthesized in $1982,{ }^{1}$ is composed of carbons with extraordinarily high surface areas and relatively uniform pore sizes. They were the ultimate material for gas-separation studies and pressure-swing absorption. However, this class of materials involves a wide variety of carbon-based adsorbants, which range greatly in their molecular sieving ability. As a matter of fact, according to Grunewald and Drago, ${ }^{2}$ they would be better described as ultramicroporous carbons, to distinguish them from the crystalline inorganic (real) molecular sieves.

The other class of carbon molecular sieves contains materials that are produced by replication, using zeolites or inorganic (siliceous and aluminosiliceous) molecular sieves as templates. In this case, their porosity is exactly

* e-mail: gpmmm@iqm.unicamp.br complementary to the ones of the molecular sieves that were used as templates; they are in fact the structural complements of inorganic molecular sieves. This review deals with this type of carbon molecular sieves. Therefore in this paper, the porous carbons produced by pyrolysis or thermal treatments of carbon precursors, WITHOUT the use of a template or a replication process will be called, following Drago's suggestions, ultramicroporous carbons (UMPC). The carbon materials prepared by replication processes from zeolites or siliceous (or aluminosiliceous) molecular sieves, that present monomodal and very narrow pore size distribution and very high surface area will be called carbon molecular sieves (CMS).

In order to introduce the reader to the subject, this paper is organized beginning with Section 2, the exposition of the methods to prepare inorganic/organic solids detailing their similarities and differences. The omnipresence of carbon materials in our daily life is confirmed in Section 3, where the modern or traditional uses of carbon in its more organized forms follow (activated carbon, ultramicroporous carbons, graphite, carbon nanotubes, etc.).

The processes of preparing carbon molecular sieves from zeolites, mesoporous inorganic molecular sieves and silica spheres through replication processes are discussed in Sections 4 to 6, indicating mainly the figures of merit in porosity of carbons thus prepared. As a natural follow-up, the reverse of the process, that is, the preparation of an 
inorganic solid from a sacrificial template, such as a carbon molecular sieve is also discussed in Section 7, with its limitations and advantages.

As expected for a prospective study, this work finishes with a discussion on the challenges still to be solved in the field (Section 8) and with one particular example of the impact these sieves might have on our lives.

\section{Organization Processes for the Preparation of Inorganic/Organic Solids}

Over time, several different processes were developed for the organization of inorganic solids or for the production of organized inorganic solids.

From all of them, three basic procedures are taken as fundamental: imprinting, templating and replication. Each one of them has particularities that make them unique. These will be detailed below.

\subsection{The molecular imprinting process}

This was introduced in the literature during the decade of 1970 by Wulff and Sharkan, who used sugar molecules to imprint polymers, ${ }^{3}$ Figure 1 . This process needs specific bonding sites in the polymers that are highly cross-linked and thus depends on the polymerization of designed monomers and/or oligomers that are organized by the template, the sugar molecule, in this context called template.

The template is the species responsible for the proper location of functional groups in what will be, at the end of the process, a functional, tailor-designed, cavity. The elimination of the template from the solid can be made by dissolution or decomposition. It is important to highlight that molecular imprinting generally affords recognition properties to the solid, that is, the cavity thus formed is capable of reversible binding of the template.
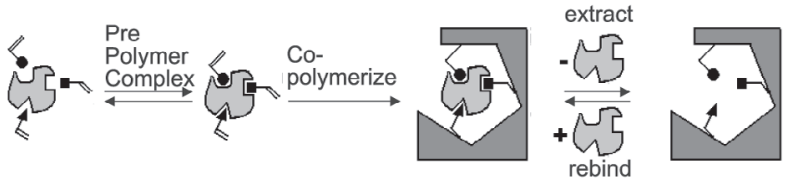

Figure 1. Imprinting process for the formation of a functional cavity in a polymer (Adapted from Ref. 3).

One major difficulty in this approach is the proper combination of functional groups to produce the polymer with active cavities. This drawback was recently overcome by the use of NOBE, ${ }^{4}$ an urea-based monomer, $N, O$ bismethacryloyl ethanolamine that, once assembled or polymerized, produced a cavity with functional capabilities for binding a large amount of templates (Figure 2).

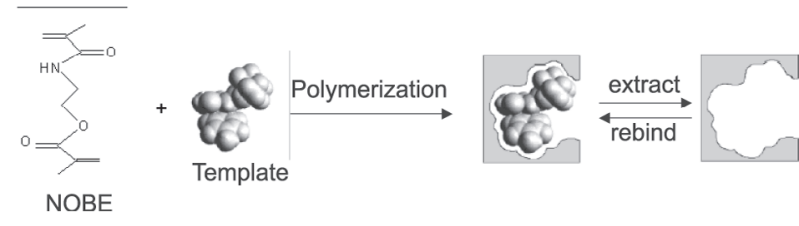

Figure 2. The "one monomer molecular imprinting process". NOBE $=N, O$-bismethacryloyl ethanolamine (Adapted from Ref. 4).

\subsection{The templating process}

Templating also appeared in the chemical literature during the decade of 1970, borrowed from the biology. In that case, the solid is built around a template molecule, much the same way as in the imprinting, but in the absence of a formal chemical bond between the template and the growing solid.

For a long time, more than 40 years, it was taken as the process responsible for the production of zeolites and molecular sieves. It was not until 1994 that Burkett and Davis ${ }^{5}$ showed that the formation of molecular sieves depended heavily on the bonding of amines or quaternary ammonium ions first to water and then to small silicate species, as shown in Figure 3, and exchanged the concept of template for structure directing agent.

In the aqueous solution of quaternary ammonium ions, tetrapropylammonium in this case, water molecules are associated with the ions through van de Waals interactions. The addition of silicate species causes the displacement of water and establishes a network of properly organized silicate species, in a high $\mathrm{pH}$ solution, that are spatially organized and ready to condense, forming the first nucleus which, and upon further condensation, leads to the formation of the zeolite framework.

Therefore, short distance interactions are the major component in the directed synthesis of molecular sieves in general, the structure directing agent has not only the role of filling the voids of the porous structure but also the function of interacting with the framework and stabilizing it, most of the time aided by water and other ions. ${ }^{6}$

In 1992, however, mesoporous molecular sieves were announced and brought the template mechanism back into the preparation of porous materials. ${ }^{7}$ Sought for since 1950, these extraordinary materials were prepared by using the liquid crystal templating method.

In that case, an ionic interaction directed the organization of small silicate species around the cationic surface of aggregates of surfactant molecules arranged in a liquid crystal phase. A pH adjustment in the system promoted the condensation of the silicate species, encasing the organic counterpart. The calcination or extraction of the surfactant produced arrays of mono or threedimensional channels in a structure that mimicked the 


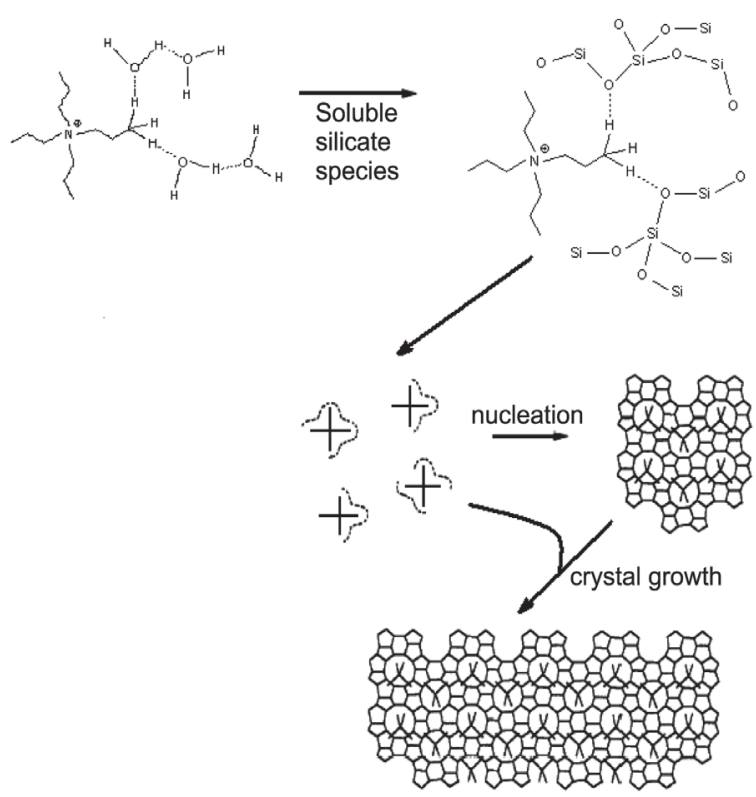

Figure 3. The formation of zeolite ZSM-5 or silicalite- 1 according to the idea by which it is the interaction of organic ions and silicate that direct the synthesis of molecular sieves (Reprinted with permission from Ref. 5, copyright 1994, American Chemical Society).

liquid crystal one, as shown in Figure 4. Under these particular reaction conditions, the solid mesoporous structure obtained depended on the temperature and on the surfactant concentration that, in the limit, determined the surfactant mesophase present in the reaction mixture, as shown by the phase diagram in Figure 5 .

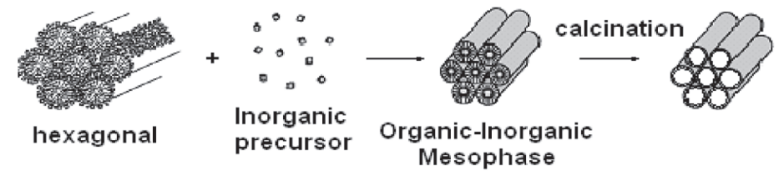

Figure 4. The formation of a solid displaying a hexagonal array of pores prepared from a cationic surfactant liquid crystal arrangement and an anionic inorganic precursor.

On the other hand, the same structures could be prepared from more diluted solutions. As a matter of fact, both mechanisms, with concentrated and diluted surfactant solutions, were proposed as possible in the first paper in the area.?

It was also shown that the initial micelles would give the hexagonal arrangement, independent of their shape, cylindrical or spherical. ${ }^{8}$

\subsection{The replication process}

Different from the above processes, in the replication process not only specific bonding sites, but the exact shape and geometry of the template are reproduced or replicated,

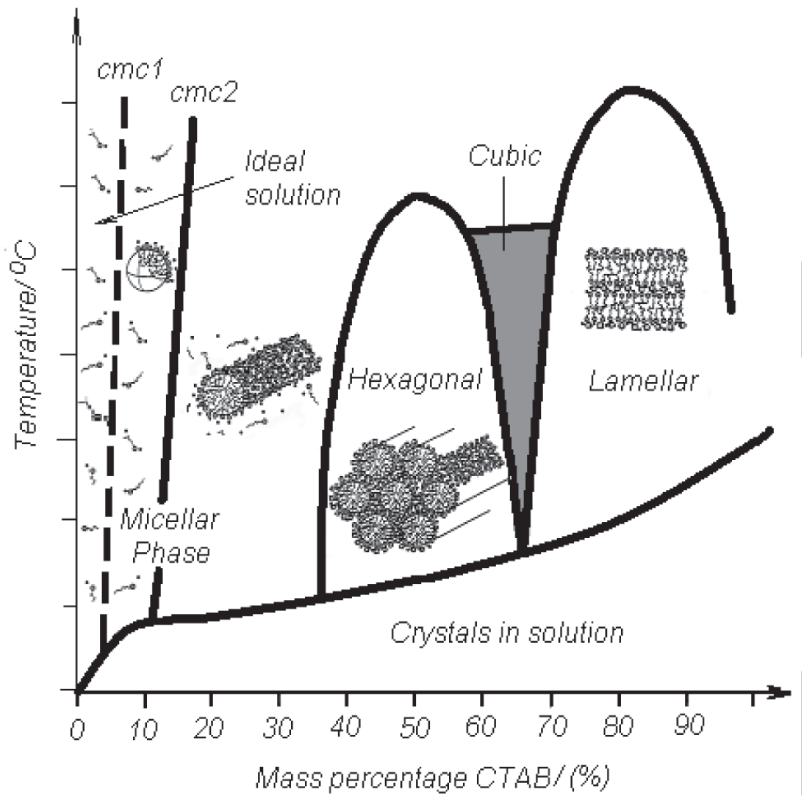

Figure 5. Phase diagram for cetyltrimethylammonium bromide at increasing concentration in aqueous solution (Adapted from Ref.1).

as well as the internal and external morphology of the template. In replication the template is not recovered; on the contrary, it is decomposed, dissolved or burned; it is therefore known as a sacrificial template. The first example of replication is the production of carbon on temperature and pressure sintered- $\mathrm{NaCl}$; cellules of $8 \mathrm{~mm}$ were produced..$^{10}$ This is the method of choice for the preparation of carbon molecular sieves.

\section{The Traditional Uses of Carbon and the Improvements Expected from the Use of Carbon Molecular Sieves}

Crystalline or amorphous carbons are widely used nowadays; several such applications are described in this section, by the type of carbon described. Mesoporous and ultramicroporous carbons, crystalline graphitic carbon and crystalline carbon nanotubes are addressed. Whenever possible, reference is made to the possible aspects that could be improved by the use of a carbon molecular sieve.

\subsection{Ultramicroporous and Mesoporous Carbons}

Air separation to produce $\mathrm{N}_{2}$ and $\mathrm{O}_{2}$ gases for various industrial purposes is commercially attained by distillation or pressure-swing adsorption (PSA) methods. For PSA or non-cryogenic methods, ultramicroporous carbons are used extensively for the separation of air into its components and their purification. These carbons are kinetic adsorbents that separate $\mathrm{N}_{2}$ from air by faster sorption of $\mathrm{O}_{2}{ }^{11}$ The results of being able to control the 
process of carbonization so as to give a particular pore structure are potentially very interesting ${ }^{12}$ for all the applications that are described below.

Ultramicroporous carbons were prepared for air separation through the carbon vapour deposition of benzene on Nomex-derived carbon fibers. ${ }^{13}$ The outstanding homogeneity of pore size provided selectivity for $\mathrm{CO}_{2}$ in relation to methane approximately 8 times superior in relation to the commercial ultramicroporous carbon Takeda 3A. Also, the selectivity of oxygen in relation to nitrogen was increased from the 5.5 obtained with commercial ultramicroporous carbon Takeda $3 \mathrm{~A}$ to 6.8 in the more homogeneous carbon.

The selectivity of Ultem ${ }^{\circledast}$ membranes to $\mathrm{CO}_{2}$ in relation to $\mathrm{CH}_{4}$ was increased $40 \%$ with the addition of $35 \mathrm{wt} \%$ of ultramicroporous carbon. Likewise, the Matrimid ${ }^{\circledR}$ membrane showed a selectivity improvement of $45 \%$, at the same loading of carbon. ${ }^{14}$ The films were also examined for the $\mathrm{O}_{2} / \mathrm{N}_{2}$ separation; it increased by 8 and $20 \%$ for carbon mixed Ultem ${ }^{\circledR}$ and Matrimid ${ }^{\circledR}$, respectively.

These two studies show unequivocally that the control of the pore sizes, performed here by post-synthesis treatments, substantially improves the selectivities of these two ultramicroporous carbons towards air components and gases in general. Such improvements in selectivity and adsorption can be even larger if one has the possibility of fine tuning the pore sizes, structure and distribution, in order to make a carbon material with sieving properties closer to the ones of the zeolites. This was made possible recently and, along with techniques to adjust pore sizes in post-synthesis treatments, is an important breakthrough in preparing even more selective, real carbon molecular sieves that present sieving properties closer to the zeolites.

Automotive catalysts are one example of catalysts that work at very high temperatures and that are supported in ceramic monoliths. This is the support of choice because it presents high tolerance to dust and to attrition, lower pressure drops and can be prepared to display a large surface area. However, the presence of $\mathrm{SO}_{2}$ and ash reduces their lifetimes. The use of carbon-coated ceramic monoliths allowed the diminution of process temperature while proving resistance to $\mathrm{SO}_{2}$. One particular catalyst, vanadium oxide, was deposited in mesoporous carboncoated cordierite monoliths and used in the selective conversion of $\mathrm{NO}$ with $\mathrm{NH}_{3}$ at low temperatures, between 90 and $180{ }^{\circ} \mathrm{C} .{ }^{15}$ The authors concluded that a nearly complete conversion was attained when the carbon layer achieved approximately $30 \mu \mathrm{m}$ thickness. Thinner layers did not allowed complete conversion and thicker ones provoked serious pressure drops. Therefore, $30 \mu \mathrm{m}$ was the best compromise between the two effects.
It is clear that if the surface area displayed by a $30 \mu \mathrm{m}-$ thick carbon layer could be obtained by a thinner porous carbon layer, then a better $\mathrm{V}_{2} \mathrm{O}_{5}$ dispersion would be possible and lower pressure drops observed. This could be achieved if the carbon layer was made of organized mesoporous carbon, or even micro-mesoporous carbon. Besides the better catalyst dispersion and higher activity in lower concentrations that could be achieved in this case, an even thinner carbon layer would possibly be necessary once the pore sizes and diameters had undergone better control.

\subsection{Crystalline, graphitic carbon}

The increase in the number of portable consumer electronics in the 1990's has had an enormous impact on portable power, especially with regard to batteries and supercapacitors. Lithium batteries, where lithium ions move from the insertion anode (carbon) and cathode $\left(\mathrm{LiCoO}_{2}\right)$, are the energy source of choice on the market for high performance rechargeable batteries. The advantages of these types of batteries are so important that lithium ion batteries have replaced $\mathrm{Ni}-\mathrm{Cd}$ batteries and made the market less prone to accept nickel-metal hydride batteries. ${ }^{16}$ The use of insertion electrodes, especially of carbon, has eliminated the problem of dendritic lithium that made the use of this sort of battery dangerous and that diminished its lifetime. In this battery, Figure $6,{ }^{17}$ lithium ions insert between layers of graphite or between layers and crevices of hard carbon.

The latter material, when used in anodes, allows for a larger acceptance of $\mathrm{Li}^{+}$ions and becomes a high capacity anode exactly because it is believed to intercalate or absorb lithium between graphene layers and in micro cavities (pores and voids).

Therefore, it is possible to conclude that the existence of sites to intercalate lithium (graphene layers or particles) is important and that the availability of these sites is a key parameter for a large anode capacity as well.

In that direction, it seems that if a carbon material with controlled porosity properties can be prepared, particularly if these properties (such as surface area and pore diameters) can be tuned into the range of interest, then specifically designed electrode materials can be produced. Such materials will present clear advantages when used in energy-storage devices. These qualities are to be found in a carbon molecular sieve.

Besides batteries, supercapacitors are also energystorage devices that find applications as memory protection in electronic circuitry and have new potential applications that include portable electronic devices, power quality and low emission hybrid cars, buses and trucks. The term supercapacitor is usually employed in describing an energy storage device based on charge storage in the electrical 


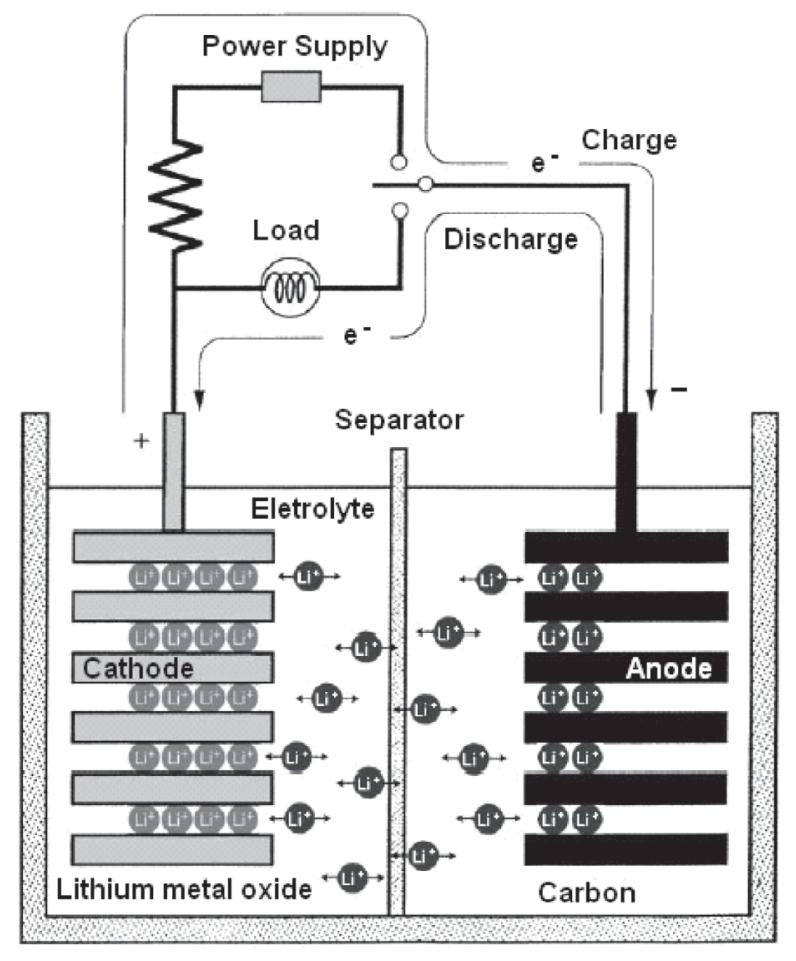

Figure 6. Principle of a lithium ion battery (Reprinted from Ref. 17, copyright 2001, with permission from Elsevier).

double layer of a high-surface-area carbon in aqueous electrolytes. The term supercapacitor has also been used to refer to the symmetric combination of high-surface-area carbon cathode and anode, filled by ruthenium dioxide. The $\mathrm{RuO}_{2}$ introduces a redox couple between two valence states of ruthenium, to result in higher capacitance for the carbon electrodes. ${ }^{18}$ Among the several methods to prepare such high-surface-area carbons with ruthenium oxide in the pores, the privileged are the ones that afford controlled surface area carbons. Patents ${ }^{19}$ have shown that replicating is one way of obtaining a higher surface area for carbon, then filling in the channels with ruthenium precursors. It has been also acknowledged that the more organized and three dimensional the carbon, the larger the specific capacitance of the $\mathrm{RuO}_{2} / \mathrm{C}$ supercapacitor. Several methods for the carbon preparation were proposed, Figure 7.

The inclusion of $\mathrm{RuCl}_{3}$ and its conversion to the oxide in several proportions and in the three different carbons were carried out. The pure carbons have specific capacitance that increases as the pore dimensionality and organization increases. Thus, mesoporous carbon 1 presented a value of $100 \mathrm{~F} \mathrm{~g}^{-1}$ of specific capacitance, while the homogeneization of the silica particles sizes increased in value by $20 \%$ and the presence of three dimensional pores increased the specific capacitance to a value of $150 \mathrm{~F} \mathrm{~g}^{-1}$.

The presence of ruthenium oxide increased the specific capacitance of the three $\mathrm{RuO}_{2} / \mathrm{C}$ to values in the range of

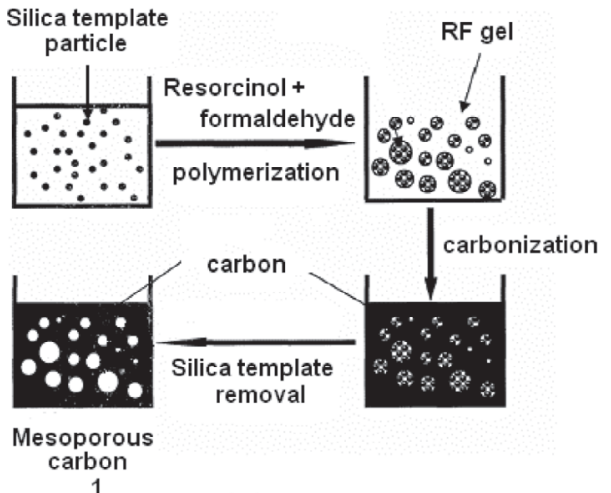

(A)

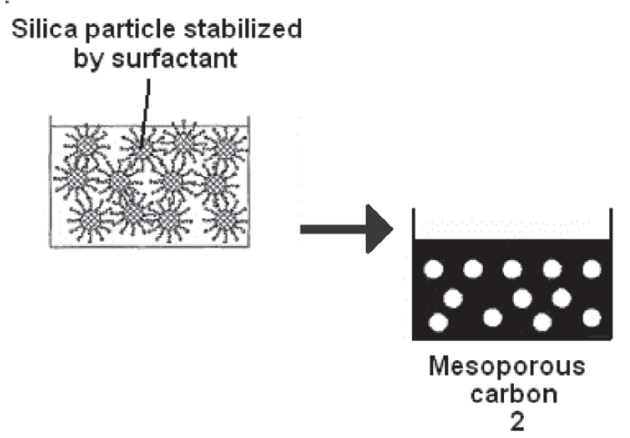

(B)

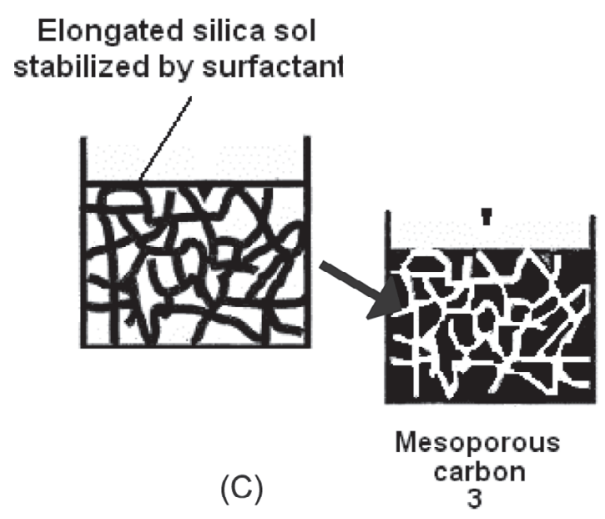

Figure 7. Three different modes of preparing porous carbons, with increasing organization. In panels (B) and (C) only the template and the final carbon material are displayed (Adapted from Ref. 19).

180-190 $\mathrm{F} \mathrm{g}^{-1}$, however the amount of $\mathrm{RuO}_{2}$ to produce this capacitance in mesoporous carbon 3 was approximately the half of what was needed to produce the same effect in mesoporous carbon $2 .{ }^{19}$

One beautiful example of the use of graphite powder is in the construction of reagentless sensors..$^{20}$ In that case, several types of organic molecules, covalently bound to the surface of the carbon electrode, present shifts of peak potential with variation of $\mathrm{pH}$. This effect is shown in Figure 8. The reaction in Scheme 1 is responsible for this variation in peak potential with $\mathrm{pH}$. 


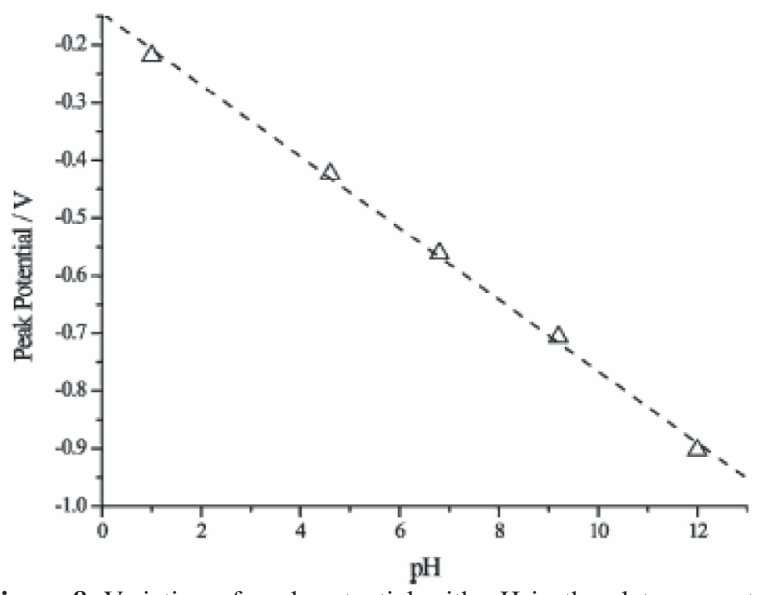

Figure 8. Variation of peak potential with $\mathrm{pH}$ in the eletropromoted dimerization of diphenylamine (Adapted from Ref. 20).

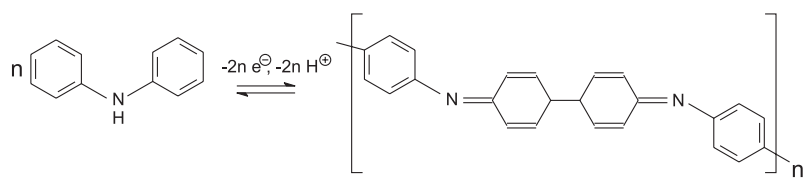

Scheme 1.

Larger variations in potential would be observed if this reaction could be promoted in carbon mesoporous molecular sieves, where the number of molecules per cavity or in the channels could be precisely controlled and determined. Also, designed reactions could be stimulated and the selectivity to molecules with specific molecular geometries could be reinforced by control of the $\mathrm{pH}$.

\subsection{Crystalline, carbon nanotubes}

Modern society depends on carbon economy to generate energy and thus adds 6.5 billions metric tons of carbon in the form of $\mathrm{CO}_{2}$ into the atmosphere,,$^{21}$ one of the most powerful greenhouse gases, capable of producing profound climate changes. One way out of this situation is the hydrogen economy: cars, industries, houses where the energy is generated by $\mathrm{H}_{2}$ which produces water when oxidized and is climate neutral.

However, whatever way one chooses to look at it, the use of hydrogen to power society, at least part of it, presents immense challenges under several points of view. One of them is the generation of $\mathrm{H}_{2}$. By far, the cheapest source of hydrogen is steam reform which breaks down natural gas into $\mathrm{H}_{2}$ and $\mathrm{CO}_{2}$ however the reformers are not very efficient, what makes them expensive sources and $\mathrm{CO}_{2}$ is still produced and has to be dealt with. The second problem to be solved is the storage of hydrogen. Because of its properties, particularly the density, to run a car on hydrogen only takes 4 times the volume of a gas tank if the car uses fuel cells because this process is twice as efficient as a gasoline internal combustion engine, ${ }^{22}$ otherwise, if the engine is still internal combustion in hydrogen, the space taken by the $\mathrm{H}_{2}$ reservoir is 8 times the tank of gasoline, for the same autonomy. Liquid hydrogen takes less room but approximately $30 \%$ of its energy is spent in compressing it to the liquid state.

Carbon nanotubes held the promise, from the beginning, to be ideal storage medium for $\mathrm{H}_{2}$. As a matter of fact, it has been shown that the property especially useful for storage in carbon nanotubes is the number of pores with less than $3 \mathrm{~nm}$ diameter, ${ }^{23}$ as shown in Figure 9.

Therefore, if a three-dimensional carbon can be produced with the largest amount of pores in the desired range then it would probably be one of the best hydrogen storage media, with a lower volume and higher storage capacity than the carbon nanotubes themselves.

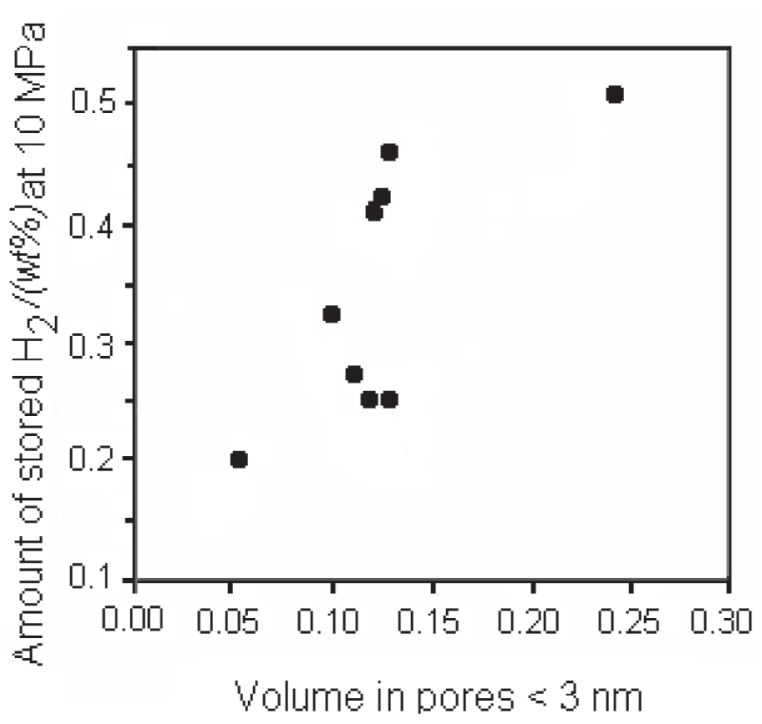

Figure 9. Capacity of hydrogen storage as a function of pore volume (Adapted from Ref. 23).

Natural gas is a viable alternative combustible for areas designated as zero emission under the Clean Air Act. Vehicles use natural gas at pressures as high as $3600 \mathrm{psi}$. The storage of gaseous combustible hydrocarbons in fact involves portable storage at low pressures and these can be developed if adsorbers are available that are capable of storaging methane at the density of the liquid. To be economically viable, the storaging systems have to store and release gas at 150 volumes per cylinder volume at 500 psi and $25^{\circ} \mathrm{C}$.

It has been shown ${ }^{24}$ that the carbons that are capable of performing accordingly are the ones with more than $50 \%$ of their pore diameters in the range of 0.8 to $2.0 \mathrm{~nm}$, more than $70 \%$ of pores with less than $2.0 \mathrm{~nm}$ and more than 95 $\%$ of pores with less than $5.0 \mathrm{~nm}$ diameter. No other material can be produced with pores having such restricted specifications as molecular sieves as well as the carbons replicated from them, the carbon molecular sieves. 


\section{Microporous Carbons from Zeolites}

These materials, which find application in storage and as supports or as electrodes, have been prepared from furfuryl alcohol, acrylonitrile, vinyl acetate and pyrene as sources of carbon and zeolites L, X, Y, ZSM-5, mordenite and beta, clays such as bentonite and MFI silicalite. Chemical vapour deposition is used after the first impregnation with one of the above carbon sources with the aim of making the impregnation more uniform.

The polymerization is performed generally by heating processes and the dissolution of the template is made in $\mathrm{HF}(40 \%)$ followed by $\mathrm{HCl}(37 \%)$.

The initial idea of synthesizing carbon in zeolites came from the preparation of the resins followed by their pyrolysis in several zeolites. ${ }^{25}$ Figure 10 shows the results of such procedures, using the phenol/formaldehyde resin (phen/form) in zeolites Y, beta and L while Table 1, shows the porosity characteristics for the zeolites and the resulting carbon materials.

It is observed that the three-dimensional zeolites produce carbon sieves that have surface areas larger than the zeolites themselves (see zeolites Y and beta in Figure 10, Panel A, and the first and second entries in Table 1) and that the monodimensional zeolite $\mathrm{L}$ gave carbon tubes with approximately half of the template surface area (Figure 10, Panel A, third entry in Table 1).

Panel B in Figure 10 shows a bimodal distribution of surface areas for the phenol/formaldehyde resin pyrolyzed at $900{ }^{\circ} \mathrm{C}$. This is probably due to an incomplete filling of
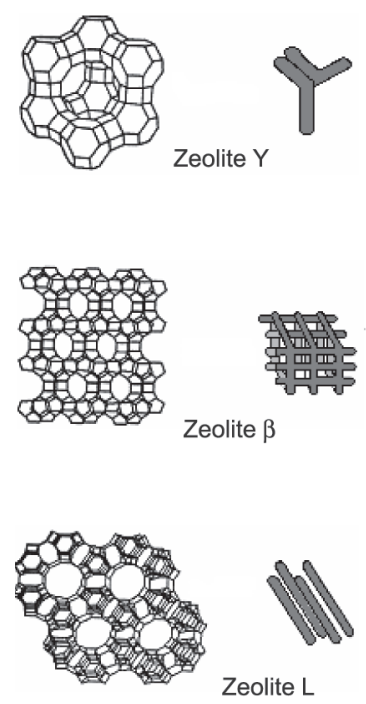

(A)

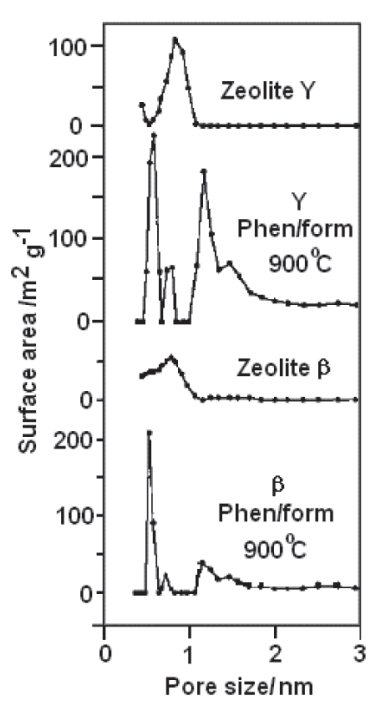

(B)

Figure 10. (A) Zeolites used as templates and the representation of the carbon materials prepared from them. (B) the pore sizes distribution of zeolites $\mathrm{Y}$ and beta and of the carbon materials (Adapted from Refs. 25 and 26).
Table 1. Porosity properties for template zeolites and the microporous carbon

\begin{tabular}{lcccc}
\hline $\begin{array}{l}\text { Zeolitic } \\
\text { Template }\end{array}$ & $\begin{array}{c}\text { Zeolite's } \\
\text { surface } \\
\text { area } \mathrm{m}^{2} \mathrm{~g}^{-1}\end{array}$ & $\begin{array}{c}\text { Carbon } \\
\text { Material }\end{array}$ & $\begin{array}{c}\text { Carbon's } \\
\text { surface } \\
\text { area } \mathrm{m}^{2} \mathrm{~g}^{-1}\end{array}$ & $\begin{array}{c}\text { Pore } \\
\text { volume } \\
\mathrm{cm}^{3} \mathrm{~g}^{-1}\end{array}$ \\
\hline Y & 488 & C-Y & 1580 & 0.83 \\
Beta & 475 & C-beta & 641 & 0.33 \\
L & 205 & C-L & 121 & 0.10 \\
\hline
\end{tabular}

the template pores with the carbon source; when the matrix is dissolved the pores that have not been filled collapse completely, generating larger pores.

Real replication of zeolite $\mathrm{Y}$ was achieved by Ma $e t$ $a l .{ }^{27}$ when propylene CVD is performed after the impregnation with furfuryl alcohol. The surface area in this case is $3600 \mathrm{~m}^{2} \mathrm{~g}^{-1}$ and the pore volumes have values of $1.5 \mathrm{~cm}^{3} \mathrm{~g}^{-1}$. The interesting aspect in this case is that the diffraction for the (111) plane is still present in X-ray diffraction for the microporous carbon. Among the microporous carbons prepared so far, this is the first case where organization is shown to that level.

\section{Mesoporous Carbons from Molecular Sieves}

In the case of mesoporous carbons, used for sensors and biosensors and as templates for oxides in supercapacitors, the carbon sources are the same as the ones used for the production of microporous solids as well as two other cheaper sources: pitch and sucrose. As templates the mesoporous molecular sieves of the type MCM, SBA and MSU are privileged, but silica gel and silica nanoparticles are also employed.

The polymerization is performed generally by heating processes, however, acid is used to assist the polymerization in the case of sucrose. Template dissolution is performed as before, in $\mathrm{HF}(40 \%)$ followed by $\mathrm{HCl}(37 \%)$.

One case of a one pot synthesis of this material, Scheme 2 has also been reported. ${ }^{28}$ In this procedure, the rate of $\mathrm{pH}$ decrease is a crucial parameter since both sucrose and silicate polymerize simultaneously. Thus, care should be taken not to favour a fast polymerization of silica because it will not entrap the sucrose nor favour sucrose polymerization because, once polymerized, the carbon source is large to be entrapped in the silica pores.

The material so obtained is not of the best quality possible in terms of porosity. The surface area of these materials is large, around $850 \mathrm{~m}^{2} \mathrm{~g}^{-1}$, of which $720 \mathrm{~m}^{2} \mathrm{~g}^{-1}$ are micropores. These carbons have large pore volumes $\left(1.1 \mathrm{~cm}^{3} \mathrm{~g}^{-1}\right)$ but present large macroporosity $\left(0.26 \mathrm{~cm}^{3} \mathrm{~g}^{-1}\right)$ probably due to packing of particles or lack of polymerization matching, as discussed above. Thus, the procedure to produce mesoporous carbons, the most organized possible, has to follow the most 


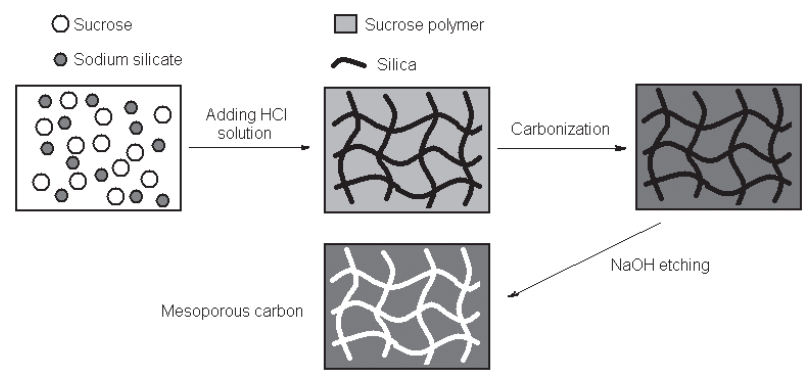

Scheme 2.

commonly used methods, the ones already used for the preparation of microporous carbons.

Starting from MCM-48, Kruk et al. ${ }^{29}$ prepared mesoporous carbons by impregnating the mesopores with sucrose in low $\mathrm{pH}$, thermally polymerizing it, pyrolysing it at $900{ }^{\circ} \mathrm{C}$ and then dissolving the silica structure. The material prepared was called CMK-1 (Carbon Mesostructure from Kaist). Figure 11 shows some characteristics of the CMK-1 prepared in our laboratory using literature procedure. ${ }^{29}$

If carbon tubes are needed, the first idea is to use MCM41 as template. However, this material presents unconnected mesopores, therefore, once filled with the carbon precursor, pyrolysed and the matrix dissolved, the carbon tubes will have no attachment to one other, and then do not remain parallel.

A solution for this situation is the use of SBA- $15,{ }^{30}$ which is also composed of parallel mesopores, the same way as MCM-41, but presents a set of micropores connecting the larger pores. In this case, when the pores are filled with the carbon precursor and the matrix is dissolved, the resulting material, called CMK-3, presents a hexagonal organization of parallel carbon tubes, Scheme 3.30,31

Figure 12 shows the transmission electron micrographs of the siliceous SBA- 15 and of the final CMK-3 where it is possible to confirm the presence of the paralell carbon rods.

Compared with the traditional particulate catalyst supports, the pore network of the synthesized mesoporous structure is not obstructed by the carbon rods but the porosity is sustained by small carbon spacers that were originated by the micropores connecting the mesopores in the SBA- 15 .

The CMK-3 has already been used as a material to support $\mathrm{Pt}$ for the cathode of a direct methanol fuel cell. The fuel cell thus prepared displayed a maximum power density of 61 $\mathrm{mW} \mathrm{cm}{ }^{2}$ at $65{ }^{\circ} \mathrm{C}$, comparable to the performance of the

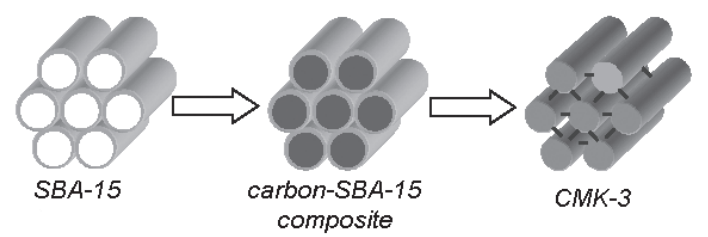

Scheme 3.

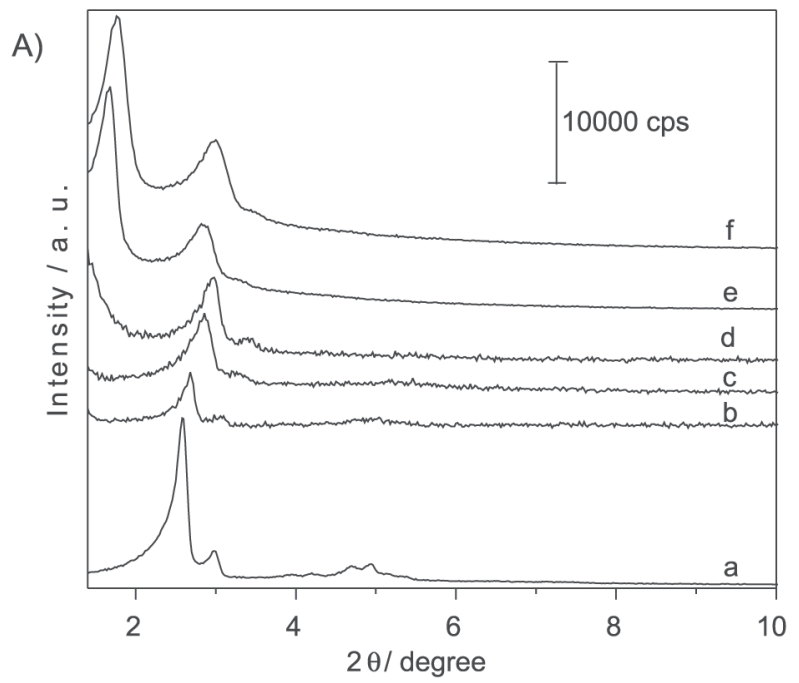

B)

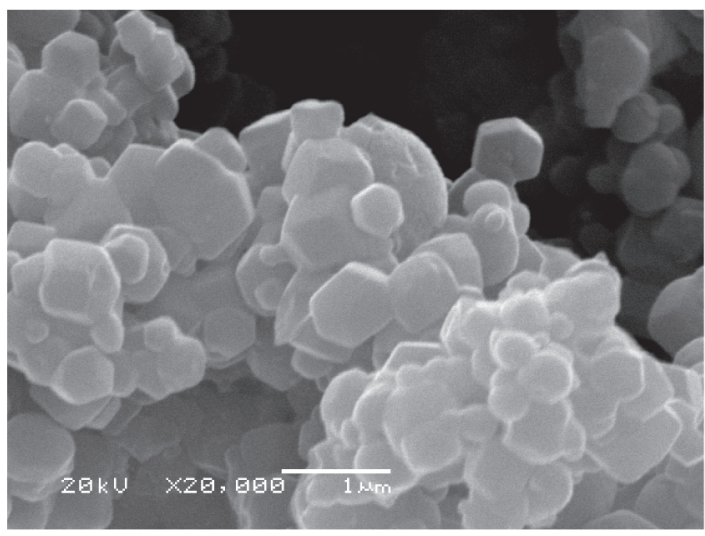

C)

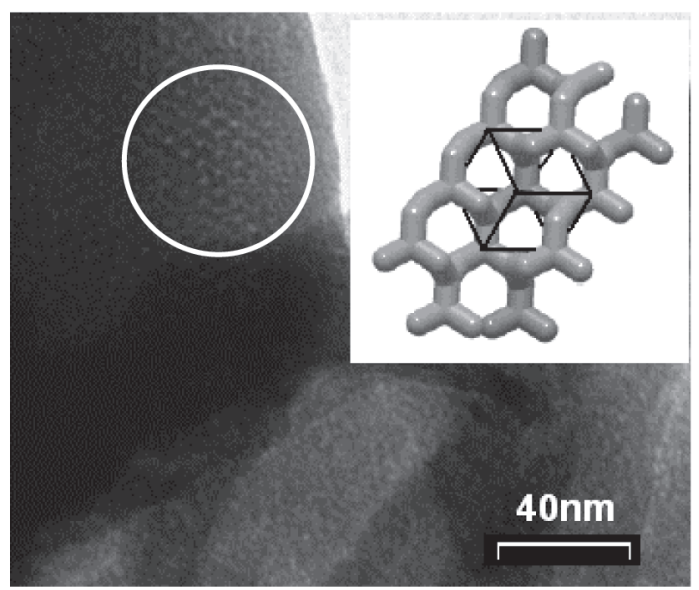

Figure 11. (A) X-ray diffraction profiles of samples that result in each step of CMK-preparation, a.) the MCM-48 template, b.) sucrose-impregnated MCM-48, c.) after pyrolysis at $600{ }^{\circ} \mathrm{C}$, d.) after pyrolysis at $900{ }^{\circ} \mathrm{C}$, e.) after dissolution of the template of sample pyrolysed at $600{ }^{\circ} \mathrm{C}$ and $\mathrm{f}$.) after dissolution of the template of sample pyrolysed at $900{ }^{\circ} \mathrm{C}$. (B) A scanning electron micrographs of CMK-1 prepared at $900{ }^{\circ} \mathrm{C}$. (C) Transmission electron micrograph of the CMK-1 prepared at $900{ }^{\circ} \mathrm{C}$. The inset shows the three dimensional structure of the pores. The circle in white shows a piece where the pores are more clearly seen; their organization corresponds to the structure in the inset. 
A)

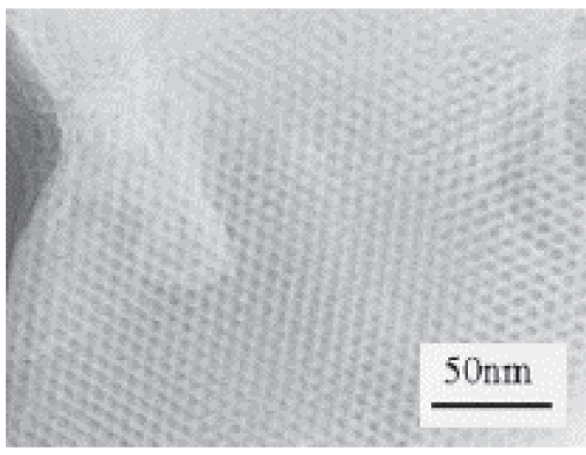

B)

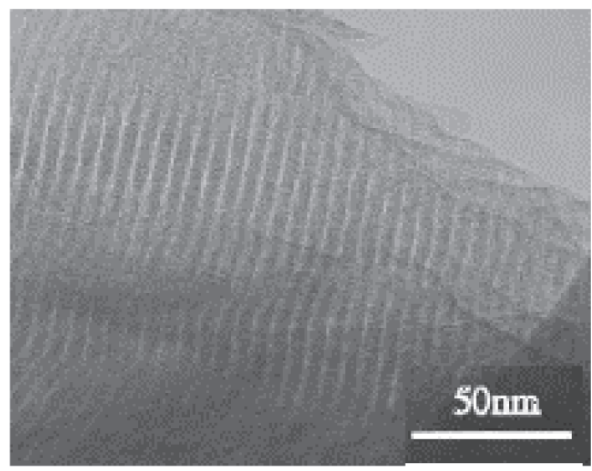

Figure 12. Transmission electron micrographs of (A) SBU-15 and (B) CMK-3 (Adapted from Ref. 30).

conventional cells at $80^{\circ} \mathrm{C}$. The authors atributed this better performance to a more effective flow of gases and liquids, probably due to the fact that the surface area of CMK-3 is 800 $\mathrm{m}^{2} \mathrm{~g}^{-1}$ while that of Vulcan XC-72 (E-tek carbon) is only 234 $\mathrm{m}^{2} \mathrm{~g}^{-1}$. Therefore, a larger surface area and/or volume of (meso)pores is interesting for catalysts supports in fuel cells.

\section{Macroporous Carbons from Silica Spheres}

In the production of porous carbons, pitch is also an option as carbon precursor in place of sugars, resins or polymers. ${ }^{32}$ In that case, meso/macroporosity imprinting occurs and can be placed either at the surface or in the bulk of particles, depending on the synthesis procedure, Scheme 4.

Spatially-resolved polymerization on silica spheres can also determine the type of porous carbon prepared. This effect can be obtained by careful control of the chemistry at the surface of the silica sphere, ${ }^{33}$ or at the interface carbon precursor-silica, Scheme 5.

The polymerization of the phenol/formaldehyde resin is an acid catalysed reaction, thus an acid catalyst in the reaction medium causes total polymerization except where the silica particles are (Path A in Scheme 5). However, if only the surface of the silica sphere is made acidic, an acid template, as for instance by reaction with aluminum tri-isopropoxide, then the polymerization will take place only at the silica-carbon precursor interface (Path B in Scheme 5). The electron

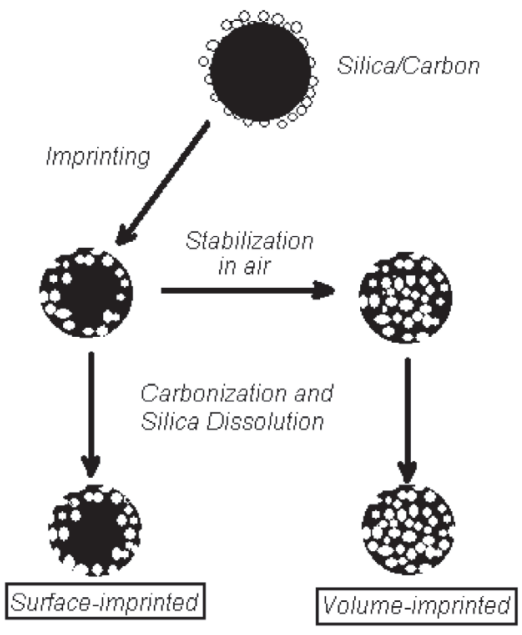

Scheme 4.

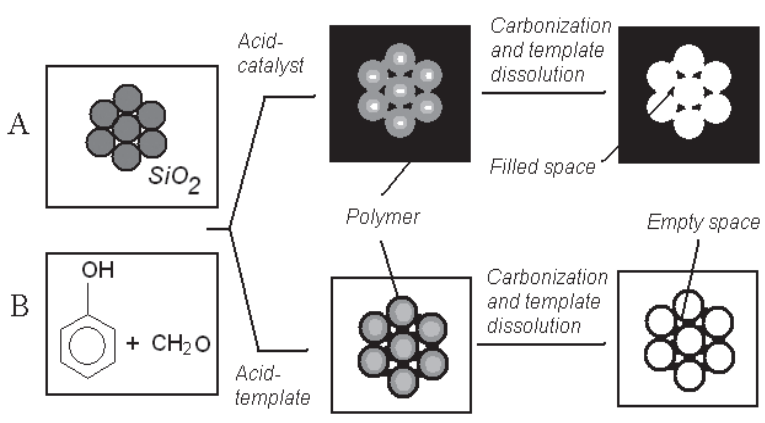

Scheme 5 .

microscopies in Figure 13 show the results of both processes.

In Figure 13A it is observed that the material resembles a hexagonal array of pores whereas Figure 13B shows a material where the carbon phase is only a layer at the surface of the particles, thus proving the possibility of spatial resolution of the polymerization/carbonization process.

\section{Porous Metal Oxides Prepared from Porous Carbons and Carbon Molecular Sieves}

\subsection{Mesoporous zeolite single crystals}

Zeolites are known as excelent catalysts and catalyst supports with one major drawback, which is the lack of reactivity towards molecules larger than their windows and pores. One way to circumvent such a disadvantage is to prepare zeolite particles with mesopores in the crystals themselves, the mesoporous zeolite single crystals. ${ }^{34}$ In order to prepare such materials, one way is to crystallize zeolites within the pores of a carbon mesoporous matrix in excess gel. Crystals are nucleated in the mesopore system and grow to large zeolite crystals around the carbon particles. Calcination eliminates the carbonaceous counterpart and liberates the zeolite mesopores (Scheme 6). 
As expected, the material exhibits a bimodal distribution of pores, with $0.09 \mathrm{~mL} \mathrm{~g}^{-1}$ of micropores with $\sim 0.5$ $\mathrm{nm}$ diameter and $1.01 \mathrm{~mL} \mathrm{~g}^{-1}$ of mesopores with diameters ranging from $5-50 \mathrm{~nm} .{ }^{34}$

The same synthesis strategy with the aid of carbon nanotubes instead of carbon mesoporous matrices, Scheme $7,{ }^{35}$ leads to longer mesopores within the zeolite single crystals. The comparison of the transmission electron micrographs in Figure 14 shows the difference in the materials obtained with both procedures and that the particle obtained is a zeolite single crystal and not an aggregate, as could be suggested by the morphology and the surface rugosity of the crystals.

A)

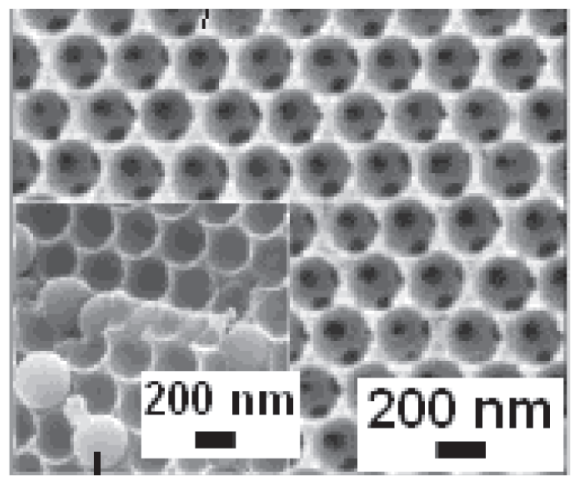

B)

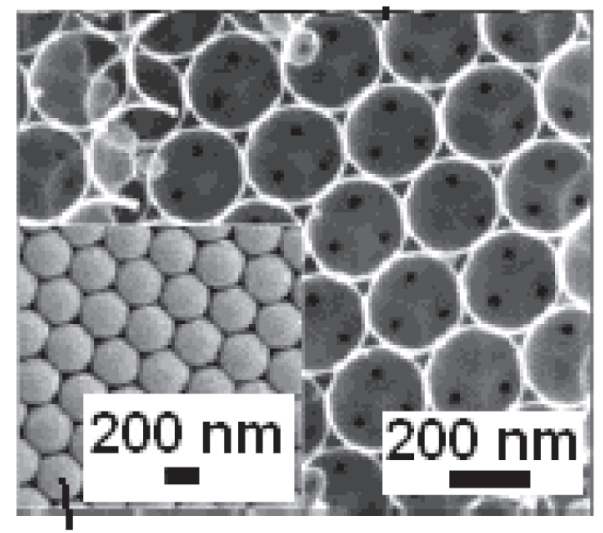

Figura 13. Electron micrographs of macroporous carbons prepared by (A) the procedure using acid catalyst (A) in Scheme 5 and (B) the procedure using acid template (B) in Scheme 5 (Adapted from Ref. 32).

\subsection{Mesoporous oxides prepared from mesoporous molecular sieves}

There is only one example of an oxide molecular sieve prepared using mesoporous carbon molecular sieve as template which is the exact reversal of the replication reaction which originated the carbon molecular sieve. It is the HUM-1 (Hannam University Mesostructure) ${ }^{36}$ whose preparation process is displayed in Scheme 8, and uses CMK-1 carbon as template.

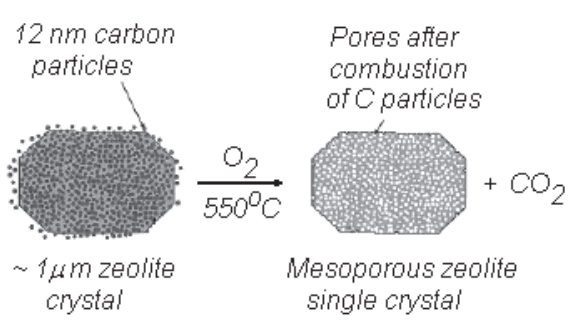

Scheme 6.

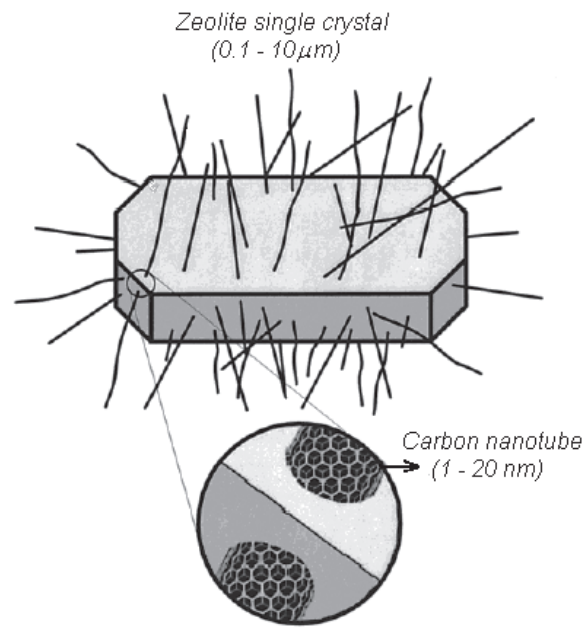

Scheme 7.

Figure 15 displays the powder X-ray diffractograms of MCM-48, the template for the mesoporous carbon, of CMK-1 prepared from the siliceous template and of HUM1 prepared from CMK-1. The three profiles display a different number of signals at small angles: MCM-48 has two well defined signals and at $2 \theta$ smaller than $3^{\circ}$ and a large envelope around $4^{\circ} 2 \theta, \mathrm{CMK}-1$ has only the first two signals at $2 \theta<3^{\circ}$ with relative intensity different from MCM-48.

This different profile has been attributed to a displacement of the interlaced pore systems during matrix dissolution. In the preparation of HUM-1 again the profile for the solid material obtained is different from either the CMK-1 or the MCM-48 initial template. Also in this case, the difference was attributed to pore system displacement during the calcination of CMK-1 to prepare the HUM-1. Despite these differences, the integrated area of the three $\mathrm{X}$-rays diffraction profiles is maintained all along the replication processes, from MCM-48 to CMK-1 to HUM-1, meaning that the overall crystallinity of the three solid phases is not lost in the transformation.

Porosity properties were also probed by nitrogen adsorption. Figure 16 displays the isotherms and pore size distributions for HUM-1 compared to CMK-1. 
A)

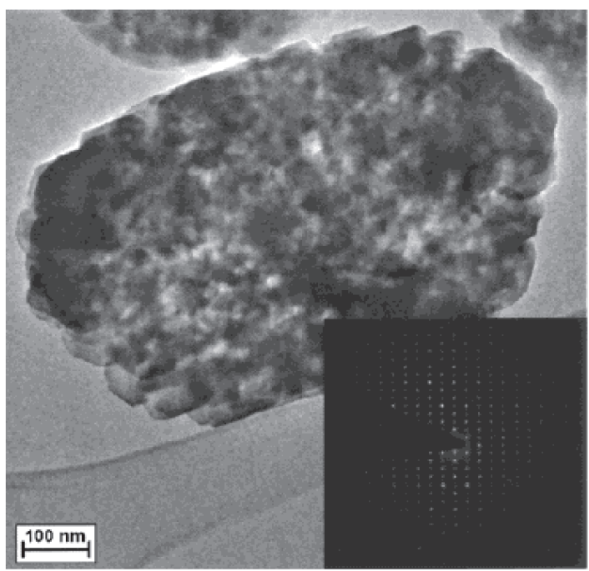

B)

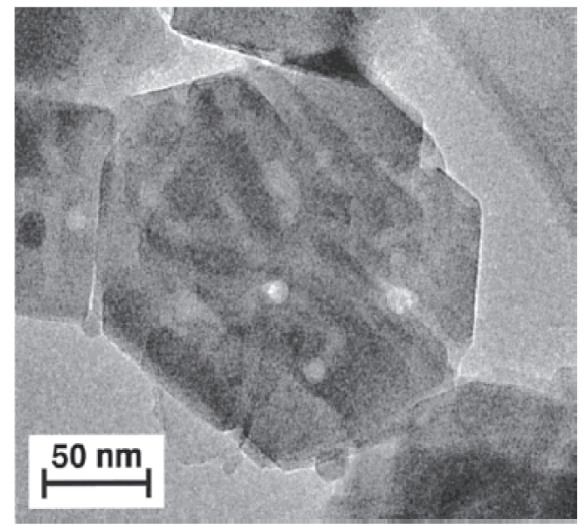

Figure 14. Transmission electron micrographs of silicalite prepared using (A) mesoporous carbon matrix according to Scheme 6 (Adapted from Ref. 34) and (B) carbon nanotubes according to Scheme 7 (Adapted from Ref. 35). The insert in Panel A shows that the particle is indeed one single crystal and not an aggregate.

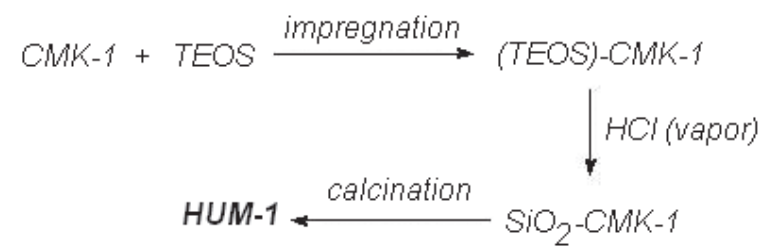

Scheme 8.

CMK-1 presents pores with a very narrow distribution of sizes which are replicated into larger pores and of a more variable size distribution. Whatever the replication results in terms of size distribution are, the porosity of the siliceous material is clear and confirms the potential of this process to produce porous materials with compositions that were difficult to obtain by conventional processes of wet chemistry.

Micro- or mesoporous catalysts with intrinsic basic properties are difficult to obtain. Such catalysts are usually prepared by post-synthesis grafting of basic compounds. ${ }^{37,38}$ Therefore, possibility to use microporous and mesoporous carbon molecular sieves as templates in replication processes comes in due time. In fact, recently CMK-3 was used as a template for the production of mesoporous $\mathrm{MgO}$ by a replication method called, by the authors, as exotemplating. ${ }^{39}$ The CMK-3 carbon was prepared from SBA-15. Figure 17 shows the powder X-ray diffraction profiles of the three materials.

Despite the apparent decreased ordering in the magnesium oxide phase as detected by XRD, the transmission microscopy showed long range order with

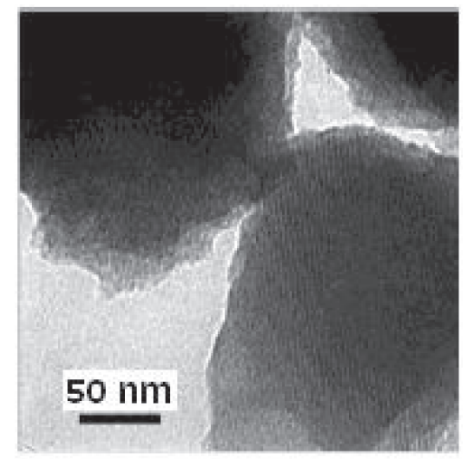

$\mathrm{MCM}-48$
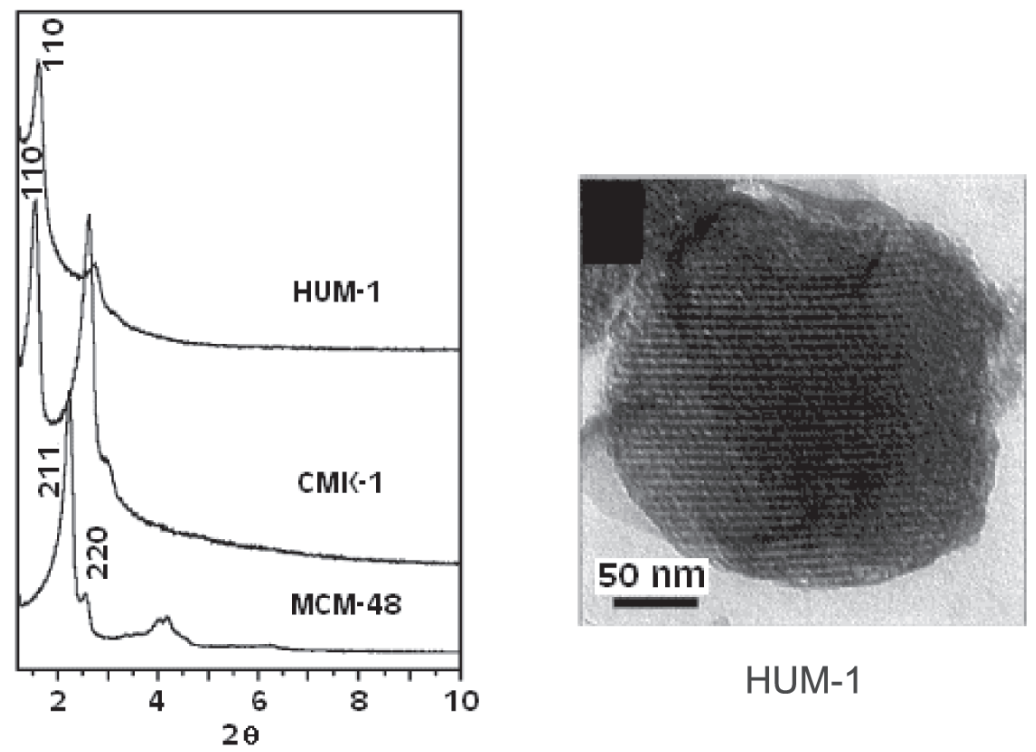

HUM-1

Figure 15. X-ray diffraction of the three solid phases obtained by consecutive replication processes, from siliceous MCM-48 to carbon CMK1 and to siliceous HUM-1, along with the transmission electron micrographs for the first and the third phases (Adapted from Ref. 36). 


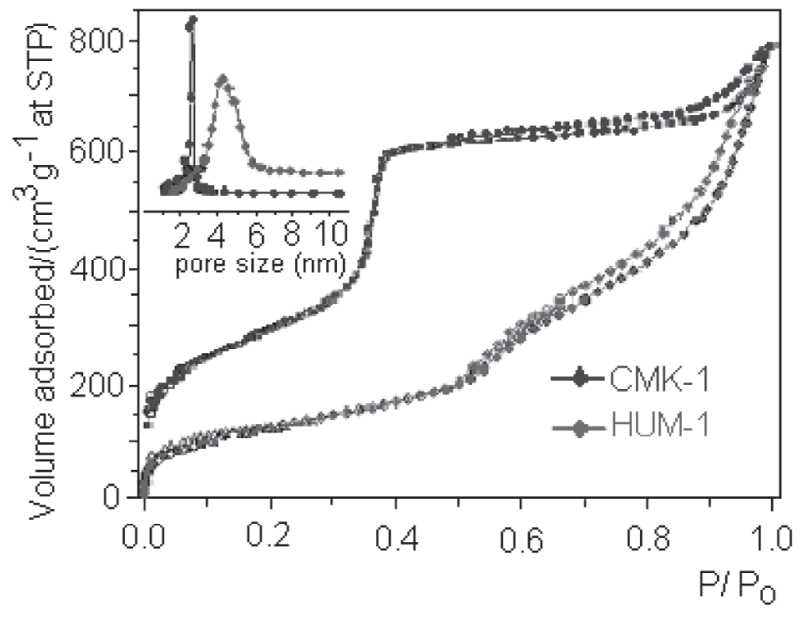

Figure 16. $\mathrm{N}_{2}$ adsorption isotherms for the CMK-1 carbon and the siliceous HUM-1. In the insert, the pore size distributions for both materials (Adapted from Ref. 36).

hexagonal symmetry of pores. Nitrogen physisorption further reveals the porous nature of the solid. The pore volume amounts to $0.51 \mathrm{~cm}^{3} \mathrm{~g}^{-1}$.

The desorption of chemisorbed $\mathrm{CO}_{2}$ in flowing helium occurs in a temperature range up to $300^{\circ} \mathrm{C}$, which confirms a degree of basicity comparable to $\mathrm{MgO}$-coated SBA-15. ${ }^{38}$

\section{Challenges and Perspectives}

As a matter of fact, the challenges in the field are more of a multiplying type in the sense that, for instance, for replication into carbon of a microporous material, the only unquestionable example is zeolite $\mathrm{Y}$, with a surface area of the order of $3000 \mathrm{~m}^{2} \mathrm{~g}^{-1}$. The replication of mesoporous materials seems to be less of a problem, however, for the replication of mesoporous carbon molecular sieves into cilicas, again only one example, the HUM-1, is known. Therefore, from this point of view, more examples are needed to confirm the general applicability of the synthesis method.

A second challenge, and the one of a more innovative character, involves the discovery of graphitization methods to organize the amorphous carbonaceous walls of the carbon molecular sieves. This would improve the conductivity of these materials. A number of papers have appeared describing the preparation of porous carbons with crystalline frameworks; despite the success in obtaining crystalline walls the surface areas reported are very poor. ${ }^{40-42}$ Therefore, this is another field that needs intense research if a porous conductive material is to be prepared.

It has been proposed that if tiny pairs of carbon cathode and anode could be assembled in three dimensional arrays,
A)

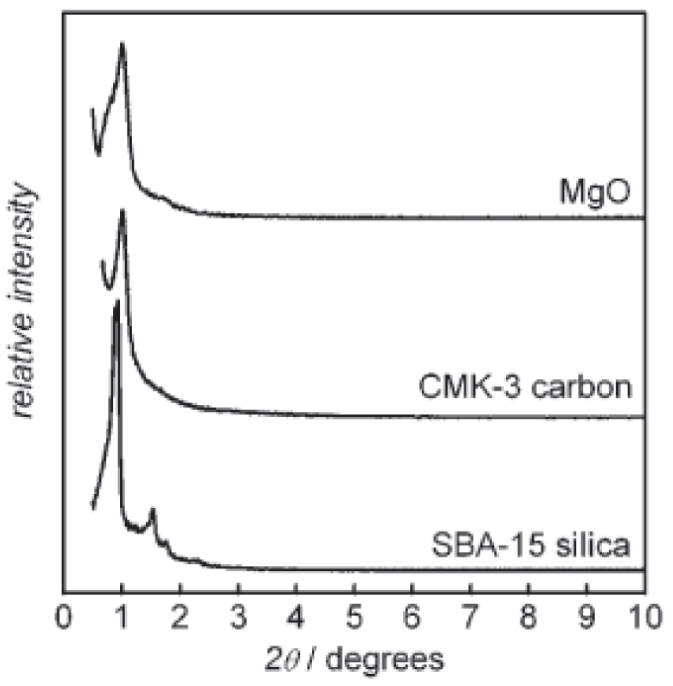

B)

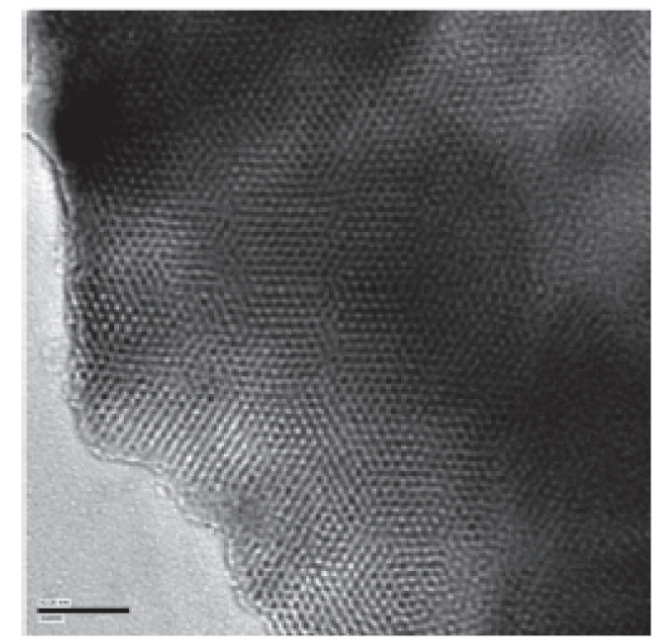

Figure 17. (A) X-ray diffraction of the parent SBA-15 silicate, of CMK-3 carbon, the exotemplate, and the $\mathrm{MgO}$ final material. (B) transmission electron microscopy of the mesoporous $\mathrm{MgO}$ (scale bar $=60 \mathrm{~nm})$ (Adapted from Ref. 39).

then the power released by the batteries could be multiplied by the number of pairs of anodes available, ${ }^{16}$ leading to even smaller palm tops, celular phones, clocks, etc. ${ }^{16}$ One way to assemble these pairs is to build them from carbon into the pores of molecular sieves that have independent, non-crossing channel systems, such as MCM-22, for instance. If other than this, the carbonaceous phase is graphitized, then three dimensional batteries will be more at hand than ever.

\section{Acknowledgments}

The authors acknowledge the work, dedication and entusiasm of several graduate and undergraduate students that are always part of the Micro and Mesoporous Molecular Sieves Group. 


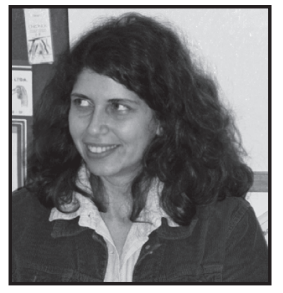

Érica Cristina de Oliveira graduated from the University of São Paulo at Ribeirão Preto, where she undertook also her Masters Degree. In 1998 she joined Prof. Pastore's group for her PhD in organometallics anchoring in zeolites and its use as catalyst for $\mathrm{C}-\mathrm{H}$ and $\mathrm{C}-\mathrm{N}$ activation. Her PostDoctoral work was mainly devoted to different procedures to obtain porous carbons where the pores walls where composed as much as possible of graphite-like moieties. She is presently working at the Aeronautics Technological Centre, at São José dos Campos, SP.

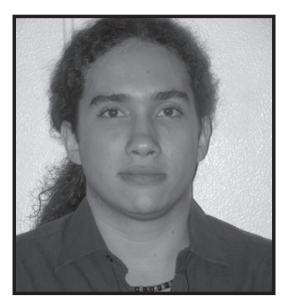

Cléo Thomás Gabriel V. M. T. Pires was born in 1983, in Brazil. He obtained his B. Sc. Degree in Chemistry (2004) at the University of Brasilia and joined the Micro- and Mesoporous Molecular Sieves Group, at Campinas, in the same year. He is presently working for his Masters Thesis on the synthesis and characterization of micro- and mesoporous carbon and others studies in the area of porous materials. In the year of 2006 he starts his Ph.D work.

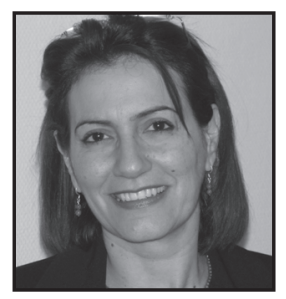

Heloise de Oliveira Pastore has been based in the Inorganic Chemistry Department, at the Chemistry Institute of the State University of Campinas, where at the moment she is Associated Professor, since 1994. Her research interests include the synthesis and modification of micro and mesoporous materials and layered structures. The organization of molecules and entities at, and by, inorganic oxide materials, especially molecular sieves are currently being actively studied in her group, with the aim at creating nanosystems capable of light emission or electronic conduction. Molecular sieves are also studied as sacrificial templates for the preparation of carbon nanoparticles or carbon molecular sieves for the use in fuel cells and electrodes in general. She is the head of the Micro- and Mesoporous Molecular Sieves Group.

\section{References}

1. Marsh, H.; Crawford, D.; O’Grady, T. M.; Wennerberg, A. N.; Carbon 1982, 15, 419.

2. Grunewald, G. C.; Drago, R. S.; J. Am. Chem. Soc. 1991, 113, 1636.

3. Wulff G.; Sharhan, A.; Angew. Chem., Int. Ed. Eng. 1972, 11, 341.

4. Sibrian-Vazques, M.; Spivak, D. A.; J. Am. Chem. Soc. 2004, 126, 7827.
5. Burkett, S. L.; Davis, M. E.; J. Phys. Chem. 1994, 98, 4647.

6. Pastore, H.O.; Munsignati, M.; Rippel, M. M.; Bittencourt, D.; Microporous Mesoporous Mater. 1999, 32, 211.

7. Kresge, C.T.; Leonowicz, M. E.; Roth, W. J.; Vartuli, J. C.; Beck, J. S.; Nature 1992, 359, 710.

8. Albuquerque, A.; Vautier-Giongo C.; Pastore, H. O.; J. Colloid Interface Sci. 2005, 284, 687.

9. Ruggles, J. L.; Holt, S. A.; Reynolds, P. A.; White, J. W.; Langmuir 2000, 16, 4613

10. Pekala R. W.; Hopper, R. W.; J. Mater. Sci. 1987, 22, 1840.

11. Hu, Z.; Vansant, E. F.; Carbon 1995, 33, 561.

12. Lenghaus, K.; Qiao, G. G.-H.; Solomon, D. H.; Gomez, C.; Rodriguez-Reinoso, F.; Sepúlveda-Escribano, A.; Carbon 2002, 40, 743.

13. Villar-Rodil, S.; Martínez-Alonso, A.; Tascón, J. M. D.; J. Colloid Interface Sci. 2002, 254, 414.

14. Vu, D. Q.; Koros, W. J.; Miller, S. J.; J. Membr. Sci. 2003, 211, 311.

15. García-Bordeje, E.; Calvillo, L.; Lazaro, M. J.; Moliner, R.; Ind. Eng. Chem. Res. 2004, 43, 4073.

16. Long, J. W.; Dunn, B.; Rolison, D. R.; White, H. S.; Chem. Rev. 2004, 104, 4463.

17. Wakihara, M.; Mater. Sci. Eng. Reports 2001, 33, 109.

18. Winter, M.; Brodd, R. J.; Chem. Rev. 2004, 104, 4245.

19. For one example see: Fine Cell and Viable Korea Co, Intern. Patent 899912001.

20. Leventis, H. C.; Streeter, I.; Wildgoose, G. G.; Lawrence, N. S.; Jiang, L.; Jones, T. G. J.; Compton, R.G.; Talanta 2004, 63, 1039.

21. Kennedy, D.; Science 2004, 305, 917.

22. Service, R. F.; Science 2004, 305, 958.

23. Bacsa, R.; Laurent, C.; Morishima, R.; Suzuki, H.; Le Lay, M.; J. Phys. Chem. B 2004, 108, 12718.

24. Westvaco Co. US. Patents 5,626,637 1995; Niagara Mohawk Power Co. US. Patents 6,225,257 1999.

25. Johnson, S. A.; Brigham, E. S.; Ollivier, P. J.; Mallouk, T. E.; Chem. Mater. 1997, 9, 2448.

26. Fuertes A. B.; Nevskaia, D. M.; Microporous Mesoporous Mater. 2003, 62, 177.

27. Ma, Z.; Kyotani, T.; Liu, Z.; Terasaki, O.; Tomita, A.; Chem. Mater. 2001, 13, 4413.

28. Han, S.; Carbon, 2003, 41, 1525.

29. Kruk, M.; Jaroniec, M.; Ryoo, R.; Joo, S. H.; J. Phys. Chem. B 2000, 104, 7960.

30. Zhao, D. Y.; Feng, J. L.; Huo, Q. S.; Melosh, N.; Fredrickson, G. H.; Chmelka, B. F.; Stucky, G. D.; Science 1998, 279, 548

31. Nam, J.-H.; Electrochem. Commun. 2004, 6, 737.

32. Jaroniec M.; Li, Y.; WO 0063722003.

33. Yu, J.-S.; Kang, S.; Yoon, S. B.; Chai, G.; J. Am. Chem. Soc. 2002, 124, 9382.

34. Jacobsen, C. J. H.; Madsen, C.; Houzvicka, J.; Schmidt, I.; Carlsson, A.; J. Am. Chem. Soc. 2000, 122, 7116. 
35. Schmidt, I.; Boisen, A.; Gustavsson, E.; Stahl, K.; Pehrson, S.; Dahl, S.; Carlsson, A.; Jacobsen, C. J. H.; Chem. Mater. 2001, 13, 4416.

36. Kim, J. Y.; Yoon, S. B.; Yu, J.-S.; Chem. Mater. 2003, 15, 1932.

37. Wang, Y.; Zhu, J. H.; Cao, J. M.; Chun, Y.; Xu, Q. H.; Microporous Mesoporous Mater. 1998, 26, 175.

38. Wei, Y. L.; Wang, Y. M.; Zhu, J. H.; Wu, Z. Y.; Adv. Mater. 2003, 15, 1943.

39. Roggenbuck, J.; Tiemann, M.; J. Am. Chem. Soc. 2005, 127, 1096.
40. Han, S.; Yun, Y.; Park, K.; Sung Y.; Hyeon, T.; Adv. Mater. 2003, 22, 1922.

41. Kim, T.; Park S.; Ryoo, R.; Angew. Chem., Int. Ed. 2003, 42, 4275 .

42. Hyeon, T.; Han, S.; Sung, Y.; Park K.; Kim, Y.; Angew. Chem., Int. Ed. 2003, 42, 4352.

Received: April 26, 2005

Published on the web: December 1, 2005

FAPESP helped in meeting the publication costs of this article. 